\title{
A ARQUITETURA DEPOSICIONAL DA FORMAÇÃO MARIZAL (CRETÁCEO INFERIOR) NA BACIA DO RECÔNCAVO, BAHIA
}

\author{
CARLOS CÉSAR UCHÔA DE LIMA ${ }^{1}$ \& GERALDO DA SILVA VILAS BOAS ${ }^{2}$
}

\begin{abstract}
THEDEPOSITIONAL ARCHITECTURE OF THE MARIZAL FORMATION (EARLY CRETACEOUS) IN THE RECONCAVO $B A S I N, B A H I A$ The Early Cretaceous Marizal Formation, which is a product of fluvial and alluvial fan systems, is about $50 \mathrm{~m}$ thick in The Reconcavo Basin, BA, Brazil. This formation changes gradually from conglomerates into sandstones and mudstones. The presence of good continuous outcrops, was essential to the architectural element analysis. This method was used to subdivide the fluvial deposits into one or more sets of nine basic three dimensional architectural elements. These elements were identified according to their lithofacies assemblage, internal geometry, and the nature of the upper and lower contacts. The study of outcrops in the proximal provided key information to identify regions the SG (sediment gravity flows) and GB (gravel bars and bedforms) elements. In the distal regions, the predominant elements are SB (sandy bedforms), LS (laminated sand sheets), DA (downstream accreted macroforms), and less frequently, CH (channels) and LA (lateral accretion deposits). The FF (floodplain fines) element has been identified in both proximal and distal regions. The distribution of these elements reveals two distinct domains in depositional model of The Marizal Formation. The first domain represents a proximal low sinuosity gravelly rivers associated with sediment gravity flows. The second domain is a result of shallow wide river channel depositional model, with sand bed load and low to intermediate sinuosity. The LS local accumulation are an evidence of flash floods in arid to semi-arid climates during deposition of the sediments.
\end{abstract}

Keywords: Marizal Formation, architectural elements, fluvial deposits

RESUMO A Formação Marizal (Cretáceo Inferior) é uma unidade derivada de sistemas fluviais e leques aluviais, que na Bacia do Recôncavo atinge no máximo $50 \mathrm{~m}$ de espessura, gradando distalmente de conglomerados à arenitos e lamitos. A boa variabilidade lateral dos afloramentos

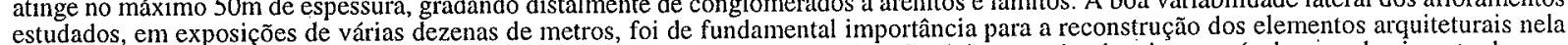
presentes. Esse método de análise de fácies, consiste em subdividir os depósitos fluviais em suítes locais, através do reconhecimento de uma ou mais sequiências de nove elementos arquiteturais básicos, identificados a partir da assembléia de litofácies, da geometria interna e da natureza dos contatos superior e inferior $\mathrm{O}$ estudo desses afloramentos revelou nas regiões proximais, a predominância dos elementos $\mathrm{SG}$ (fluxos gravitacionais de sedimentos) e GB (barras e formas de leito cascalhosas). Distando da fonte, aparecem os elementos arenosos, onde predominam os elementos SB (formas de leito arenosas), LS (lençóis de areia laminada), DA (macroformas de acrescimento para jusante) e menos freqüientemente os elementos LA (depósito de acrescimento lateral) e CH (canais). O elemento lamoso FF (finos da planície de inundação) ocorre em toda área estudada. A distribuição desses elementos e das fácies que os constituem, revelam dois domínios para o modelo deposicional da Formação Marizal. O primeiro representa rios cascalhosos, proximais de baixa sinuosidade, associados a depósitos de fluxos gravitacionais de sedimentos. O segundo é o resultado de rios dominados por canais rasos e largos, com carga de leito arenosa e de sinuosidade baixa a intermediária. Acumulações locais do elemento LS, são evidências da ocorrência de inundações rápidas em climas áridos a semi-áridos durante a deposição dos sedimentos que compõem a Formação Marizal.

Palavras-chaves: Formação Marizal, elementos arquiteturais, depósitos fluviais

INTRODUÇ̃̃O A Formação Marizal, foi assim denominada por Brazil (1947), para designar uma seção praticamente horizontal de arenitos grossos e conglomerados, que ocorrem na Serra do Marizal, Bacia de Tucano. Santos (1962) mapeando a parte sudeste da Bacia de Tucano, mediu uma seção bem mais representativa, determinando por meio de pólens encontrados em folhelhos carbonosos, a idade Albiano Inferior a Aptiano (Cretáceo Inferior), para a Formação Marizal. Almeida \& Ghignone (1962) e Ghignone (1963), descrevem essa formação na Bacia de Tucano Central e atribuíram para a mesma, uma espessura máxima de $108 \mathrm{~m}$ na região estudada, constatando também que toda a parte central da Bacia de Tucano é coberta por sedimentos pertencentes a essa unidade litológica. A Formalização da Formação Marizal, foi proposta por Viana et al. (1971), com a revisão estratigráfica das Bacias de Tucano e do Recôncavo, que incluíram os sedimentos estudados por Brazil (1947) e por Santos (1962). Lima \& Vilas Boas (1990), são os primeiros a estudarem alguns afloramentos da Formação Marizal em termos de elementos arquiteturais. Lima (1991), faz um estudo detalhado sobre essa formação na Bacia do Recôncavo, caracterizando-a como uma seqüência de sedimentos depositados por rios entrelaçados proximais. Lima \& Vilas Boas (1994), caracterizam os mecanismos de transporte e deposição dos conglomerados pertencentes a essa unidade sedimentar e Lima \& Vilas Boas (1996), descrevem e interpretam os agentes formadores das litofácies arenosas da unidade.

Uma das principais ocorrências da Formação Marizal na Bacia do Recôncavo, está entre as cidades de Camaçari e Dias Dávila (Fig.1a). Nessa região, foi feito um estudo das melhores exposições desta formação, que aflora como pequenos morrotes ou penhascos, variando em média entre 5 e $10 \mathrm{~m}$ de altura (máximo de $30 \mathrm{~m}$ ), e de algumas a várias dezenas de metros de extensão (máximo de $180 \mathrm{~m}$ ). A boa variabilidade lateral dos seus afloramentos, constituíram uma excelente oportunidade para o estudo em detalhe da Formação Marizal e as suas principais exposições estão indicadas no mapa geológico (Fig.1b).

Esse trabalho objetiva reconstruir detalhadamente as condições paleoambientais que dominaram durante a deposição da Formação
Marizal na região estudada, descrevendo-a e caracterizando-a, segundo a análise dos elementos arquiteturais que a compõe. Além disso, foi feito um levantamento em detalhe das direções de paleocorrentes e padrões de dispersão dos sedimentos à época de deposição desta unidade sedimentar.

MÉTODOS DE TRABALHO Os trabalhos de campo foram feitos, utilizando o método desenvolvido por Miall (1985), que visa a identificação do que ele chamou de elementos arquiteturais. Miall (op. cit), sugeriu a existência de pelo menos oito tipos básicos desses elementos em depósitos fluviais, identificados a partir da assembléia de litofácies, da geometria interna e da natureza dos contatos superior e inferior que limitam o elemento. Cowan (1991), estudando a Morrinson Formation (EUA), divulgou um novo elemento arquitetural, ao qual denominou de "hollow" (elemento HO) que representa o preenchimento de escavações na junção entre dois ou mais canais. Miall (1996), incorporou esse novo elemento aos identificados anteriormente. Este elemento não foi observado na Formação Marizal. A extensão lateral de dezenas a centenas de metros dos afloramentos permitiu a utilização de fotomosaicos dos mesmos para o traçado das superfícies limitantes e demais informaçōes acessíveis.

Em ambiente fluvial, as superfícies que limitam as diversas litossomas, geram uma hierarquia de escalas, mostrada na Tabela 1 (Miall 1988, 1996). A simbologia para as litofácies arenosas e conglomeráticas (Tabela 2) foram adaptadas por Lima (1991), Lima \& Vilas Boas (1994) e Lima \& Vilas Boas (1996). A Tabela 3 mostra as principais características dos elementos arquiteturais, exibindo também o código que os identificam e que é usado nesse trabalho, nas interpretações dos perfis. Os dados das paleocorrentes são indicados por setas e são plotados em relação a orientação do afloramento, que é mostrada por uma seta maior na base de cada ilustração. Esse método foi utilizado por Miall \& Turner-Peterson (1989).

FEIÇÓES ARQUITETURAIS Os afloramentos da Formação Marizal na Bacia do Recôncavo, variam aproximadamente de 5 a $12 \mathrm{~m}$ em altura e de 30 a $180 \mathrm{~m}$ em extensão. Nessa escala é possível obser-

1 - Departamento de Ciências Exatas. Universidade Estadual de Feira de Santana, Km. 03 BR 116 CEP 44031-460, Feira de Santana, Bahia Brasil. email: uchoa@ uefs.br.

2 - Laboratório de estudos Costeiros - Curso de Pós Graduação em Geologia, CPPG/IGEO/UFBA, Rua Caetano Moura 123, Federação CEP 40210-350, Salvador Bahia Brasil. E-mail: gsvboas@pppg.ufba.br. 


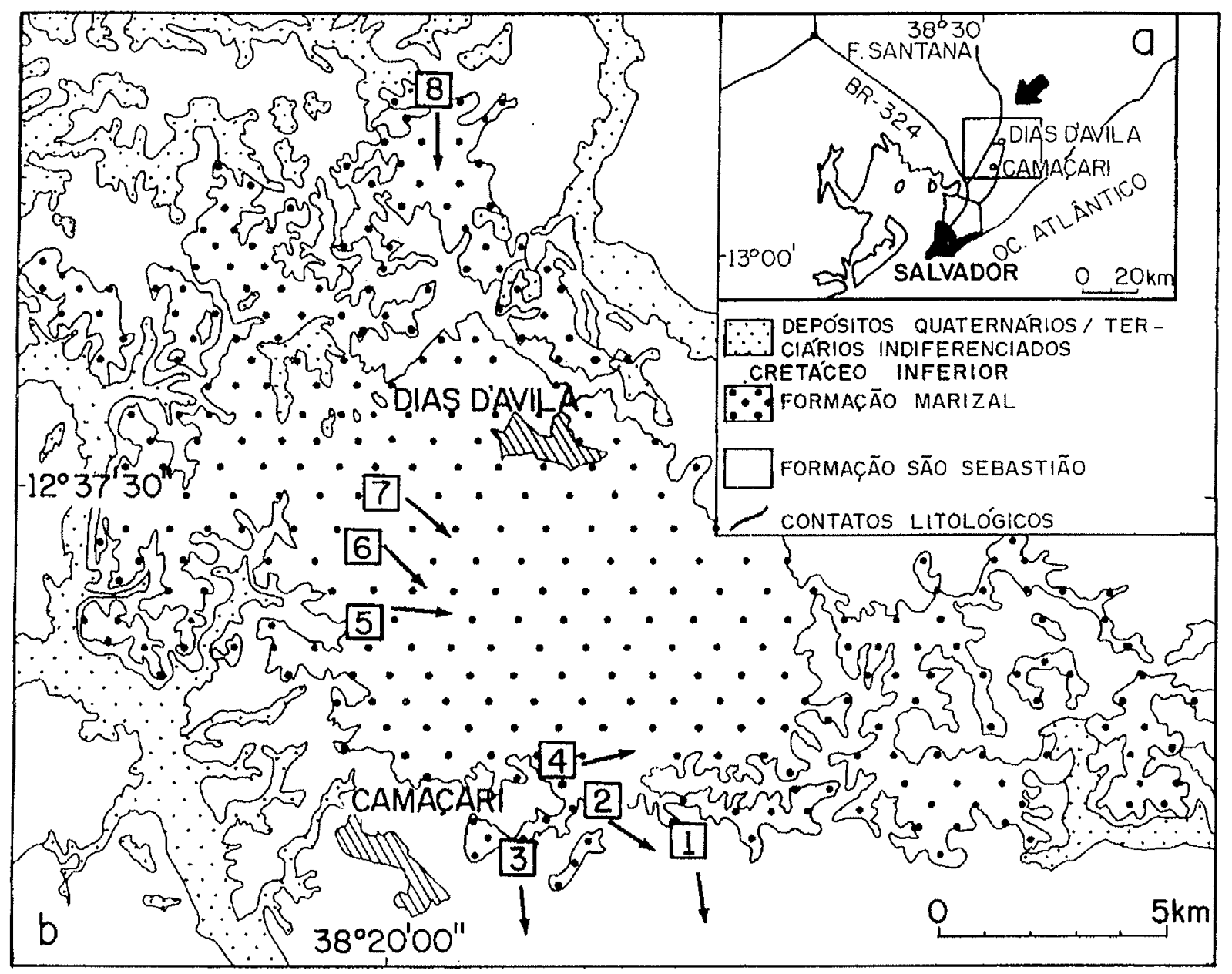

Figura I-A. localização da ârea estudada; B. Mapa geológico simplificado, com a indicação dos afloramentos estudados e das dirę̧óes de paleocorrentes para cada un deles.

Tabela 1 - Hierarquia das superfícies limitantes em depósitos fluviais (Miall 1988).

\begin{tabular}{|c|c|c|}
\hline Ordem & Composiçẫo da Litussuma & Geometrial \\
\hline 1 & sequuência individual de cstratos cruzados. & lençôs, cunlass, lentes. \\
\hline 2 & co-scquência das litofácies. & Iençбis, cunhias, lentes. \\
\hline 3 & jucrementos de crescimento das macroformas. & $\begin{array}{l}\text { cunlta com basc platta c superffeic } \\
\text { deposicional supcrior mergulthando } \\
\text { suavemente }\left(15^{\circ}\right)\end{array}$ \\
\hline 4 & $\begin{array}{l}\text { macrolormas (ex. depósilos de acrescimento hateral, } \\
\text { depósitos de acrescimento para jusante). }\end{array}$ & $\begin{array}{l}\text { cunla, lentes, com basc plana e } \\
\text { superficic deposicional superior } \\
\text { convexa para cima. }\end{array}$ \\
\hline 5 & canais $\mathrm{e} \mathrm{sistemas} \mathrm{de} \mathrm{canais.}$ & $\begin{array}{l}\text { Iençbis, fitas, com base plana ou } \\
\text { concava para cima. }\end{array}$ \\
\hline 6 & $\begin{array}{l}\text { sistemas deposicionais (subdivis Jes cstratigráícas } \\
\text { mapétivcis). }\end{array}$ & lençúuis. \\
\hline
\end{tabular}

var em perfis construídos a partir de fotomosaicos, todos os elementos arquiteturais propostos por Miall (1985). As superfícies limitantes visualizadas na escala dos afloramentos, variam de ordem 2 a 5 . Os dados de paleofluxo, estão sumariados na Tabela 4, representados pelos vetores médio e magnitude segundo Curray (1956). Foram selecionados as melhores exposições da Formação Marizal na área estudada, objetivando definir os elementos arquiteturais mais comuns presentes naquela região. A localização desses afloramentos é mostrada na fïgura $1 \mathrm{~b}$. A seguir será feito um sumário dos elementos arquiteturais encontrados nos principais afloramentos, descrevendo primeiro, os elementos arquiteturais conglomeráticos (que predominam na faixa sul da área estudada), e em seguida os elementos arenosos e lamosos.

A figura 2 ilustra uma das maiores exposições observadas (afloramento 04), e onde foram identificados cinco elementos arquiteturais. Foi difícil definir a hierarquia da maioria das superfícies limitantes presentes, pelo fato de que muitas delas, ocorrerem nos conglomerados. No entanto, as superfícies visivelmente erosivas, foram traçadas com linhas mais grossas, o que poderia significar uma superfície de $3^{\mathrm{a}}$ ordem, caso se transferisse a hierarquia adotada por Miall (1988), para os conglomerados. As linhas com traço mais fino não possuem caráter erosivo, sendo normalmente menos irregulares. $O$ traçado das superfícies de maior ordem, aparece por vezes truncado, devido a pequenos desmoronamentos ocorridos no afloramento. No entanto, para a definição das superfícies de $5^{\mathrm{a}}$ ordem, foi necessária por vezes, a observação da continuidade dessas superfícies $\mathrm{em}$ afloramentos vizinhos. Muitas das litofácies arenosas no afloramento 4, são maciças ou com estruturas de deformação penecontemporâneas, e apesar da presença de pequenos falhamentos sindeposicionais , a maioria das superfícies limitantes está disposta horizontalmente. Uma superfície de $5^{\mathrm{a}}$ ordem é observada na parte inferior do afloramento e separa os conglomerados do elemento GB, dos arenitos subjacentes. Outras superfícies de $5^{\mathrm{a}}$ ordem, horizontais a levemente inclinadas, espaçadas cerca de $2 \mathrm{~m}$ uma da outra separam os elementos arquiteturais arenosos acima dos conglomerados.

Elementos arquiteturais identificados GRAVITACIONAIS DE SEDIMENTOS (SG)

FLUXOS arquitetural é muito comum na faixa sul (afloramentos 2, 3, 4 e 5), com exposição mais característica no afloramento 2 (Figura 3), e aparece representado principalmente pelas litofácies $\mathrm{Cmc}$ e Cma, e secundariamente pela litofácies cmf (veja Tabela 2). A composição dos clastos é variável, aparecendo desde clastos intra-basinais até fragmentos de rochas metamórficas bandadas, quartzitos e rochas básicas. Os conglomerados são de forma desorganizada, separados muitas vezes, por superfícies erosivas irregulares com concavidade voltada para cima (superfícies dispostas em canais). Algumas superfícies limitantes pla- 
Tabela 2 - Classificą̧ão das litofácies (modificado de Miall 1978, 1996). Os símbolos entre parênteses, são os originais em língua inglesa.

\begin{tabular}{|c|c|c|c|}
\hline Código de fácies & litofácies & $\begin{array}{l}\text { estruturas } \\
\text { sedimentares }\end{array}$ & interpretação \\
\hline Aa $(S t)$ & $\begin{array}{l}\text { areia fina a muito grossa, } \\
\text { pode ser seixosa. }\end{array}$ & 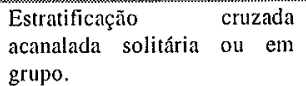 & Dunas lingóides (3D) com crista sinuosa. \\
\hline Ap $(S p)$ & $\begin{array}{l}\text { areia fina a muito grossa, } \\
\text { pode ser seixosa. }\end{array}$ & $\begin{array}{l}\text { estratificação cruzada planar } \\
\text { solitária ou em grupo. }\end{array}$ & $\begin{array}{l}\text { Formas de leito transversais e ondas de } \\
\text { areia (2D). }\end{array}$ \\
\hline $\mathrm{Ao}(\mathrm{Sr})$ & areia muito fina a grossa. & laminação cruzada & $\begin{array}{l}\text { marcas onduladas (regime de fluxo } \\
\text { inferior). }\end{array}$ \\
\hline $\mathrm{Ab}(\mathrm{Sl})$ & areia muito fina a grossa & $\begin{array}{l}\text { estratos cruzados de baixo } \\
\text { ângulo }\left(<15^{\circ}\right) \text {. }\end{array}$ & Dunas e barras lavadas \\
\hline Ah $(\mathrm{Sh})$ & areia muito fina a grossa. & $\begin{array}{l}\text { Laminação horizonta! plano- } \\
\text { paralela. }\end{array}$ & $\begin{array}{l}\text { Fluxo em leito plano (regime de fluxo } \\
\text { superior). }\end{array}$ \\
\hline Ahi (Shi) & $\begin{array}{l}\text { areia fina a média, pode ser } \\
\text { seixosa }\end{array}$ & $\begin{array}{l}\text { laminação } \quad \text { horizontal } \\
\text { irregular. }\end{array}$ & $\begin{array}{l}\text { Migraçăo de ondulaçóes geradas por } \\
\text { açăo dos ventos. }\end{array}$ \\
\hline $\mathrm{Fm}(\mathrm{Fm})$ & lama, silte, argila. & Maciço & $\begin{array}{l}\text { depósitos de transbordamento ou } \\
\text { "drapes" }\end{array}$ \\
\hline $\mathrm{Fl}(\mathrm{Fl})$ & areia, silte, lama. & $\begin{array}{l}\text { Laminação fina, ondulações } \\
\text { muito pequenas. }\end{array}$ & $\begin{array}{l}\text { Depósitos de transbordamento ou de } \\
\text { descida da inundação. }\end{array}$ \\
\hline $\mathrm{Cmc}(\mathrm{Gci})$ & $\begin{array}{l}\text { conglomerados maciços } \\
\text { suportados por clastos. }\end{array}$ & $\begin{array}{l}\text { Estruturas } \\
\text { imbricação. }\end{array}$ & $\begin{array}{l}\text { Depósitos de fluxos de detritos } \\
\text { pseudoplásticos. }\end{array}$ \\
\hline Cma (Gmg) & $\begin{array}{l}\text { cascalhos maciços suportados } \\
\text { por matriz arenosa. }\end{array}$ & $\begin{array}{l}\text { Estruturas canalizadas } \\
\text { imbricação, gradação. }\end{array}$ & $\begin{array}{l}\text { Depósitos de fluxos de detritos } \\
\text { pseudoplásticos mais diluídos. }\end{array}$ \\
\hline $\mathrm{Cmf}(\mathrm{Gmm})$ & $\begin{array}{l}\text { cascalhos maciços suportados } \\
\text { por matriz lamosa. }\end{array}$ & Gradaçẳo incipiente. & $\begin{array}{l}\text { Depósitos de fluxos de detritos } \\
\text { verdadeiros. }\end{array}$ \\
\hline Cec (Ghe) & $\begin{array}{l}\text { cascalhos estratificados } \\
\text { suportados por clastos } \\
\text { (bimodais). }\end{array}$ & $\begin{array}{l}\text { Acamamento horizontal, } \\
\text { gradação, imbricação. }\end{array}$ & $\begin{array}{l}\text { Depósitos de tapetes de tração (barras } \\
\text { longitudinais). }\end{array}$ \\
\hline Cem (Ghm) & 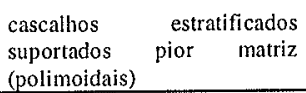 & $\begin{array}{l}\text { acamamento horizontal, } \\
\text { laminação de baixo ângulo, } \\
\text { imbricação, gradação. }\end{array}$ & $\begin{array}{l}\text { Depósitos de tapetes de tração mais } \\
\text { diluídos (barras longitudinais). }\end{array}$ \\
\hline
\end{tabular}
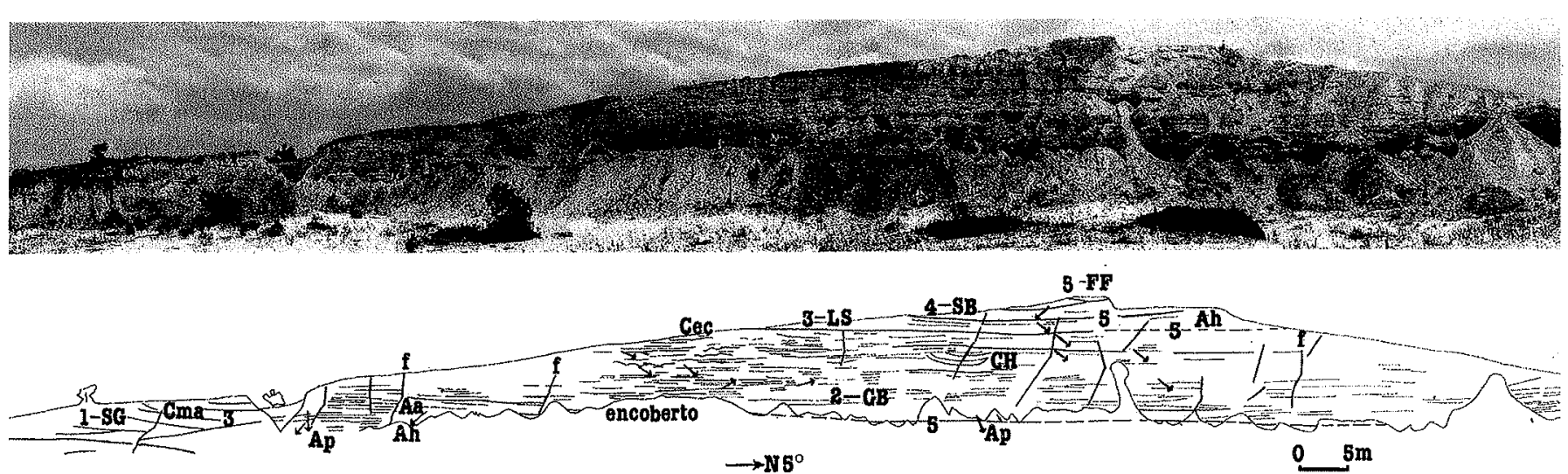

Figura 2 - Fotomosaico e perfil lateral da exposição mais extensa da Formação Marizal (afloramento 04) na área estudada. 3, 5 : hierarquia das superfícies limitantes (ver Tabela 1); $\rightarrow$ direção das paleocorrentes; Aa, Cec: código de litofácies (ver Tabela 2); 2-GB,4-SB: código para elementos arquiteturais (ver Tabela 3 ); $\rightarrow N 5^{\circ}:$ Orientação do afloramento; $f:$ falha.

nas e mais contínuas, de hierarquia maior que as superfícies das feições canalizadas, dão um aspecto tabular aos conglomerados. Para cada intervalo entre as superfícies planas de maior continuidade, existem várias superfícies limitantes internas. As litofácies $\mathrm{Cmc}$ e Cma, possuem uma faixa granulométrica que varia de grânulos até matacões de $70 \mathrm{~cm}$ de comprimento. $\mathrm{Na}$ litofácies $\mathrm{Cmf}$ no entanto, os maiores clastos não passam de pequenos calhaus. As direções das paleocorrentes obtidas a partir da imbricação dos cascalhos para o afloramento 2 , dão um vetor médio para $105^{\circ}$ (veja Tabela 4), que está perfeitamente compatível com as medidas efetuadas nos demais afloramentos. Foram feitas 37 medidas, dando um vetor magnitude de $74 \%$, mostrando excelente orientação dos clastos das litofácies que compõem o elemento SG no afloramento 2 . Em alguns locais nesse afloramento, os conglomerados sobrepõem a arenitos com deformações penecontemporâneas. O contato entre ambos é uma superfície irregular, com desníveis de até $3 \mathrm{~m}$. Onde os conglomerados se sobrepõem aos arenitos do elemento DA, que possuem estruturas preservadas (sem deformações penecontemporâneas), os desniveis não são tão grandes. No afloramento 5, esse elemento é representado por um conglomerado laminado imerso nos arenitos fluviais, com feições de fluxo gravitacional (fluxo de lama). Além de laminado, o conglomerado é suportado por uma matriz areno-lamosa (litofácies $\mathrm{Cmf}$ ), de forma irregular e com intraclastos de argila.

BARRAS E FORMAS DE LEITO CASCALHOSAS (GB) O elemento GB ocupa a maior porção do afloramento 4 (veja Figura 02), se estendendo desde a sua parte esquerda, até a extremidade direita. Esse elemento tinha continuidade no afloramento vizinho (hoje destruído), que ficava a uma distância de aproximadamente $100 \mathrm{~m}$. O elemento GB está inserido entre dois pacotes arenosos e possui espessura máxima em torno de $9 \mathrm{~m}$. As litofácies que compõem o elemento GB são Cec e $\mathrm{Cem}$, intercaladas com litofácies arenosas. Uma superfície limitante de ordem 5 , contínua em todo o afloramento, mas, em muitos locais, encoberta por desmoronamentos, o separa do arenito inferior. Superfícies erosivas ocorrem entre as litofácies conglomerática e arenosa, e, uma delas, evidencia um pequeno canal com cerca de $2 \mathrm{~m}$ de profundidade. Esse canal ocorre na parte central do afloramento 04 (Fig. 02). Na parte superior esquerda do elemento, há uma superfície erosiva, irregular, com desníveis decimétricos. Acima desta predominam superfícies erosivas menos irregulares. Hierarquicamente, a primeira pode representar uma superfície de ordem 4 (incisão de canais menores), enquanto que as demais, são de ordem 3 . Separando os conglomerados 
dos elementos superiores, existe uma superfície de quinta ordem, que representa a base do elemento LS. Diversas medidas de paleocorrente foram efetuadas a partir da imbricação relativamente bem desenvolvida em muitas das camadas individuais dos conglomerados. $O$ vetor médio obtido mostrou tendência geral de fluxo segundo o azimute N62 $2^{\circ}$. Para as trinta e sete medidas efetuadas, obteve-se um vetor magnitude de $48 \%$, o que mostra uma boa orientação preferencial dos clastos (Tabela 4).

LENÇÓIS DE AREIA LAMINADA (LS) O elemento LS aparece em apenas três ocasiões (afloramentos 4,5 e 8). A principal litofácies presente é $\mathrm{Ah}$, associada comumente a arenitos apresentando laminações convolutas. A litofácies $\mathrm{Ab}$ aparece secundariamente enquanto que camadas pouco espessas das litofácies Ao, Aa e Ap completam o conjunto de litofácies desse elemento. A granulometria da litofácies Ah, varia de areia fina a grossa com grânulos e seixos imersos. Algumas superfícies internas (de segunda ordem) foram observadas, separando as co-sequências das litofácies Ao e Aa das camadas de Ah e Ab. Esta última, aparece no afloramento 5 , em camadas de até $1,2 \mathrm{~m}$ de espessura com mergulho de $5^{\circ}$ na direção $N 90^{\circ}$. Para o afloramento 4 , o vetor médio resultante possui sentido para sudeste com azimute de $N 98^{\circ}$. Para as nove medidas efetuadas, o vetor magnitude foi $65 \%$, mostrando boa orientação preferencial para as estruturas sedimentares presentes no elemento LS. O afloramento 5 mostra vetor médio com azimute de $\mathrm{N} 102^{\circ}$, compatível com as direções encontradas para o afloramento 4. O vetor magnitude calculado, foi de $85 \%$ para um total de treze medidas, o que dá uma orientação preferencial excelente para as estruturas que compõem o elemento LS.

FORMAS DE LEITO ARENOSAS (SB) Este elemento aparece geralmente associado ao elemento LS, predominando a litofácies Aa (figura 4; afloramento 8). Esta apresenta muitas variantes no que diz respeito a granulometria e aos tamanhos das seqüências, sendo composta em alguns casos por arenito fino a médio bem selecionado ou ainda por arenitos conglomeráticos extremamente mal selecionados (Lima \& Vilas Boas 1996). O tamanho individual das sequêencias varia de uma co-sequiencia para a outra, sendo observadas sequêencias dèsde 10 até $60 \mathrm{~cm}$ de espessura e de $40 \mathrm{~cm}$ até $3,5 \mathrm{~m}$ de largura. Secundariamente aparece a litofácies Ap, com seqüências menos espessas. Em alguns locais aparecem associados à litofácies $\mathrm{Aa}$, arenito maciço ou com laminações convolutas. Falhas sin-deposicionais com pequeno rejeito e com continuidade de alguns metros foram observadas nesse elemento.

Para o afloramento 5, o tamanho das seqüências individuais aumenta para cima. Assim, as co-seqüências na base do elemento, são constituídas por seqüências que não ultrapassam $10 \mathrm{~cm}$ de espessura, enquanto que nas co-seqüências que ocupam o topo do elemento, as seqüências individuais podem atingir até $30 \mathrm{~cm}$ de espessura. Superfícies limitantes de $2^{\mathrm{a}}$ ordem são comuns, com as superfícies de $3^{\mathrm{a}}$ ordem aparecendo raramente. Um total de 18 medidas de paleocorrentes foram efetuadas nesse afloramento, que deram um vetor médio para leste $\left(\mathrm{N} 84^{\circ}\right)$, estando este concordante com a direção regional das paleocorrentes. O vetor magnitude calculado foi de $94 \%$, mostrando excelente orientação preferencial das estruturas preservadas. Para o afloramento 6 , obteve-se vetor médio de $\mathrm{N} 131^{\circ}$, a partir de trinta e duas medidas efetuadas nos estratos cruzados. $O$ vetor magnitude obtido foi de $62 \%$, mostrando boa orientação preferencial das estruturas sedimentares preservadas.

MACROFORMAS DE ACRESCIMENTO PARA JUSANTE (DA) O elemento DA aparece nos afloramentos 1,2,5 e 7. Neste elemento arquitetural, a litofácies Ap predomina sobre as demais, aparecendo em co-sequências que possuem espessuras variando entre 1 e $1,7 \mathrm{~m}$, com sequêencias individuais atingindo um máximo de $50 \mathrm{~cm}$. Em muitas cosequências, foi observado aumento para cima das espessuras das sequiências individuais. As superfícies limitantes internas observadas são de $2^{\mathrm{a}}$ e $3^{\mathrm{a}}$ ordem, e, comumente separam a litofácies Ap de outras litofácies. O ângulo de inclinação das camadas frontais na litofácies $\mathrm{AP}$, variam de acordo com o tamanho das sequiências individuais. As maiores (mais espessas que $30 \mathrm{~cm}$ ), possuem o ângulo de inclinação das camadas frontais mais baixos (menor que $25^{\circ}$ ), enquanto que nas seqüências menores, o ângulo de inclinação das camadas frontais, são comumente maiores que $30^{\circ}$. As seqüências agrupadas de estratos cruzados, aparecem separadas por finas camadas de siltito (litofácies $\mathrm{Fl}$ ), que variam de 1 à $10 \mathrm{~cm}$ de espessura. Lamitos de cor branca e ricos em caolim (litofácies Fm), são comuns sobre os estratos cruzados isolados. Em direção paralela às paleocorrentes, as superfícies limitantes podem se dispor horizontalmente, ou podem mergulhar suavemente, tanto no sentido das paleocorrentes, como no sentido oposto.

A predominância de superfícies limitantes horizontais, e a presença de algumas sequiências da litofácies Aa, torna, muitas vezes, difícil a
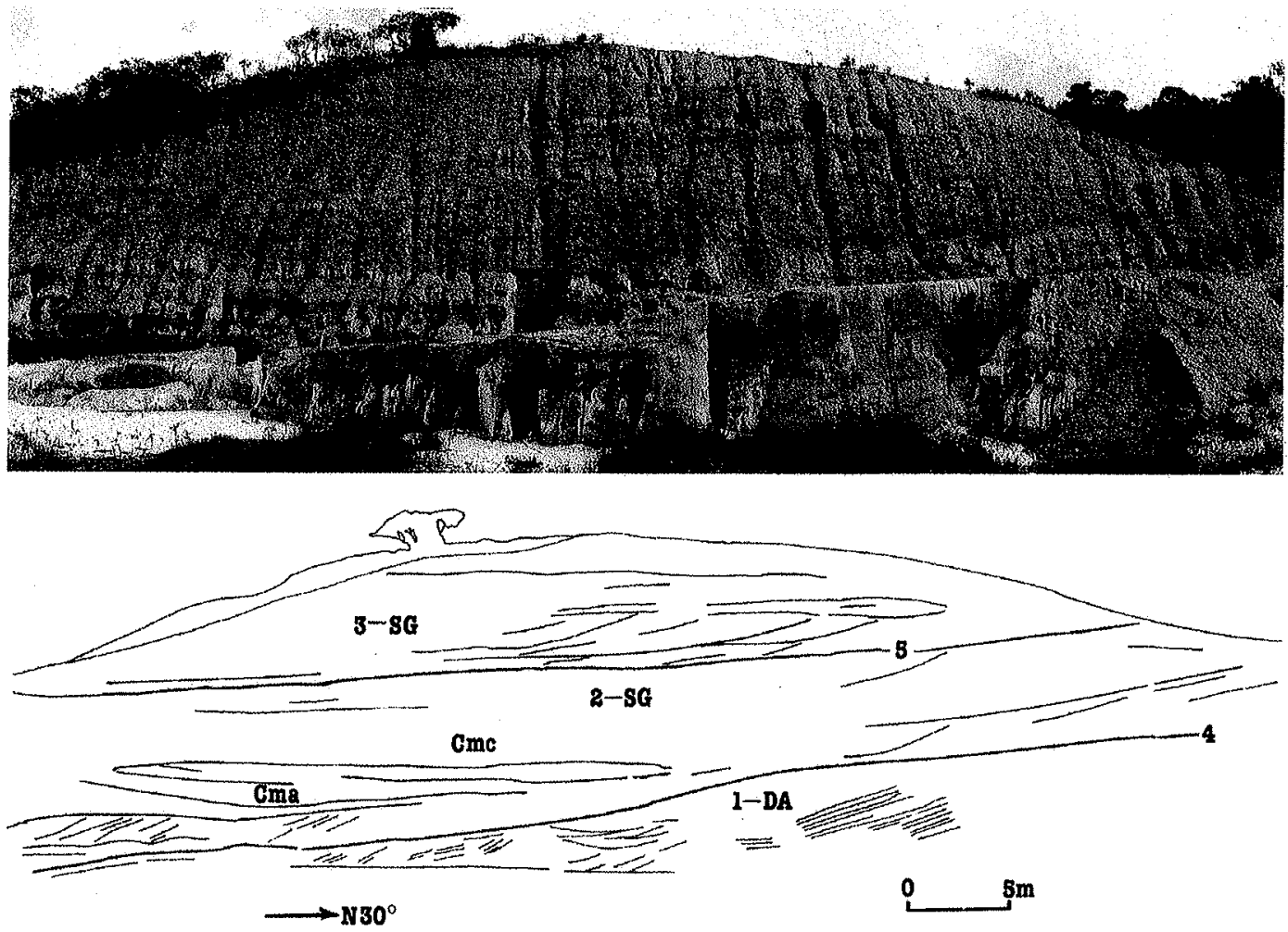

Figura 3- Fotomosaico e perfil lateral do afloramento 02. Nessa exposição, há o predomínio do elemento SG. 5: hierarquia das superficies limitantes (ver Tabela 1); Cmä, Cmc: código de litofácies (ver Tabela 2); I-DA,2-SG: código para elementos arquiteturais (ver Tabela 3); $\rightarrow N 30^{\circ}:$ Orientação do afloramento. 
Tabela 3 - Elementos arquiteturais em depósitos fluviais (Miall 1996).

\begin{tabular}{|c|c|c|c|}
\hline Elemento & Símbolo & $\begin{array}{l}\text { Assembléia principal de } \\
\text { litofácies }\end{array}$ & $\begin{array}{l}\text { Geometria } \\
\text { e relacốes }\end{array}$ \\
\hline canais & $\mathrm{CH}$ & qualequer combinaļăo & 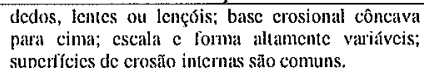 \\
\hline $\begin{array}{l}\text { barras c lormas de leito } \\
\text { cascalhoso }\end{array}$ & GB & $\mathrm{Cec}, \mathrm{Cem}$ & $\begin{array}{l}\text { lentes, lençós; corpos normalmente tabulares; } \\
\text { comumente intercumados. Conn SB. }\end{array}$ \\
\hline Iormas de leito arcnosas. & SB & $A a l, A p, A h, A b, A v$ & $\begin{array}{l}\text { Iencs, lençois, cunhas; ocorrem como } \\
\text { precenchimento e rompinento de camais, topo de } \\
\text { bauras c barras menores. }\end{array}$ \\
\hline $\begin{array}{l}\text { macroformas de acresci- } \\
\text { mento para jusinte }\end{array}$ & DA & Aal, $A p, A l l, A b, A 0$ & $\begin{array}{l}\text { lentes repousando cm base plana on com as super- } \\
\text { lícies limitantes internas ( } 3^{\sharp} \text { ordem) c superior ( } 4^{\underline{a}} \\
\text { ordem) possuindo convexidade voltada para cima. }\end{array}$ \\
\hline $\begin{array}{l}\text { depósitos de acrescimento } \\
\text { lateral. }\end{array}$ & LA & $\begin{array}{l}\text { Ail, Ap, Al, Ab, Ao menos } \\
\text { comumente c, } I \text {. }\end{array}$ & 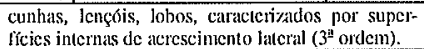 \\
\hline $\begin{array}{l}\text { Precnchimento de cscava- } \\
\text { cocs (scour lollow) }\end{array}$ & HO & Cec, Cem, Cma, Aal, Ab. & $\begin{array}{l}\text { Escavaçăo cm forma de collice com procenchimento } \\
\text { assimerico }\end{array}$ \\
\hline $\begin{array}{l}\text { lluxos gravitacionais de } \\
\text { sedimentos. }\end{array}$ & SG & Cme, Cma, Cmil & lobos, lençois; tipicamente interacantudos com GB. \\
\hline Iençsis de arcia laminada. & LS & $\begin{array}{l}\text { Ah, Ab, com Aat, Ap c Ao } \\
\text { menos conum. }\end{array}$ & Ienç̧óis, lábuals. \\
\hline finos de transbordamento & FF & Fin, Fl. & $\begin{array}{l}\text { lábuas Jinhls al cspessas; comumente interacamidoto } \\
\text { com SB; pode precnether canais abandonados. }\end{array}$ \\
\hline
\end{tabular}

Tabela 4 - Litofácies e dados de paleocorrentes para os perfis selecionados. " granulometria: $m f, f, m, g, m g$ = muito fina, fina, média, grossa, muito grossa, $n^{b}=$ número de medidas de paleocorrentes.

\begin{tabular}{|c|c|c|c|c|c|}
\hline Elemento & Jitofácies & Granulometria & $n^{6}$ & Vetor médio & $\begin{array}{l}\text { Vetor magnitude } \\
(\%)\end{array}$ \\
\hline \multicolumn{6}{|l|}{ Afloranchito l } \\
\hline I - DA & Ap, Ail & l-mg & 15 & 171 & 84 \\
\hline $2-\mathrm{CH}$ & $A p, A i l, A 0, A b$ & $m y r-m g$ & $\ldots$ & --... & ---- \\
\hline \multicolumn{3}{|c|}{ perlil total } & 15 & 171 & 84 \\
\hline \multicolumn{6}{|c|}{ Afloramento 2} \\
\hline I-DA & $A p, A_{0}$ & f - cascalloo & 8 & 196 & 96 \\
\hline $2-S G$ & Cinc, Cma, Cinl & cascalloo & 37 & 105 & 74 \\
\hline \multicolumn{2}{|c|}{ pertïl total } & & 45 & 121 & 63 \\
\hline \multicolumn{6}{|c|}{ Alloramento 3} \\
\hline 1-SG (a) & Cma & calscillho & 18 & 339 & 61 \\
\hline $1 \cdot S G(b)$ & Cinc & cascallor & 14 & 100 & 20 \\
\hline \multicolumn{2}{|c|}{ pervil toral } & & 32 & 172 & 31 \\
\hline \multicolumn{6}{|c|}{ Afloramento 4} \\
\hline I. SG & Cmc, Cma & cascullo & -.. & $\ldots$ & --- \\
\hline $2-G B$ & $\mathrm{Cec}, \mathrm{Ccm}$ & casciallo & 37 & 62 & 48 \\
\hline $3 \cdot L S$ & $A h, A b, A n, A a t, A p$ & $i-g$ & 9 & 98 & 65 \\
\hline $4-S B$ & Ail & $l-m g$ & 5 & 110 & 98 \\
\hline $5-F F$ & Fin & lamá & $\cdots$ & $\cdots$ & -..- \\
\hline \multicolumn{3}{|c|}{ pertil total } & 51 & 76 & 53 \\
\hline \multicolumn{6}{|c|}{ Alloramento 5} \\
\hline $1-L S$ & $A h, A b, A p, A o$ & $i-m g$ & 13 & 102 & 85 \\
\hline $2-S G$ & $\mathrm{cmi}^{\mathrm{c}}$ & cascallono & $\ldots$ & & ---- \\
\hline $3-\mathrm{SB}$ & Aa & $i-g$ & 18 & 84 & 94 \\
\hline $4-\mathrm{DA}$ & $A p, F, F m . A o$ & mlco - mg, lama & 9 & 102 & 97 \\
\hline \multicolumn{3}{|c|}{ pertil total } & 40 & 94 & 91 \\
\hline \multicolumn{6}{|c|}{ Alloramento 6} \\
\hline $1-S B$ & Aa & f - cuscalho & 32 & 131 & 62 \\
\hline \multirow[t]{2}{*}{$2-L A$} & Ap, An, All & $m I-m g$ & 9 & 141 & 83 \\
\hline & & & 41 & 134 & 67 \\
\hline \multicolumn{6}{|c|}{ Alloramentos 7} \\
\hline $1-D A$ & A:l, $A p$ & $\mathrm{l}-\mathrm{mg}$ & 18 & 132 & 84 \\
\hline \multicolumn{6}{|l|}{ Allorancento 8} \\
\hline $1-S B$ & Aal, $A p$ & $j$ - ciscallho & 4 & 172 & 99 \\
\hline $2-S B$ & Aal, $\mathrm{Ap}$ & $i$ - cascallho & 7 & 185 & 99 \\
\hline $3-L S$ & Alt, A & $m i-m g$ & 1 & 172 & $\ldots$. \\
\hline $4-S B$ & A:il, Ap & j- calscatho & 3 & 163 & 95 \\
\hline
\end{tabular}

caracterização desse elemento, que pode ser confundido com o elemento SB. Entretanto, foi observado nos afloramentos 2 e 5 que a litofácies Ap, com seqüências de estratificação cruzada planar estão associadas a superfícies limitantes superiores de $4^{\text {a }}$ ordem, com convexidade voltada para cima, caracterizando assim o elemento DA. A litofácies Aa presente no afloramento 4, possui espessura máxima da seqüências de $30 \mathrm{~cm}$. O caráter pouco festonado dessas estruturas, torna difícil a diferenciação delas de estratos cruzados planares, sendo necessário na maioria das vezes, a observação de cortes perpendiculares a direção das paleocorrentes para se obter uma caracterização mais segura.

CANAIS (CH) Este elemento, aparece mais significativamente em apenas uma ocorrência da Formação Marizal na Bacia do Recôncavo (afloramento 1). Essa feição apresenta algumas superfícies côncavas para cima, que se truncam, evidenciando a migração de um único canal durante a deposição dos sedimentos. A profundidade medida do canal foi de $3 \mathrm{~m}$, enquanto que a largura não pode ser observada na sua totalidade. Mesmo assim, o acompanhamento lateral do canal, revelou largura superior a $60 \mathrm{~m}$. Não só o tamanho das estruturas, como também a granulometria, diminuem da base para o topo do canal. Estratos cruzados planares e acanalados com espessura das sequeências de até $25 \mathrm{~cm}$, e granulometria variando de areia fina a granulosa, foram observados. No topo, apenas estratos cruzados menores aparecem (máximo de $10 \mathrm{~cm}$ de espessura), com granulometria predominantemente de areia fina. Além das litofácies Ap e Aa, são observadas no topo, as litofácies $\mathrm{Ao}$ e $\mathrm{Al}$, todas migrando com ângulos variando de $20^{\circ}$ a $40^{\circ}$ em relação as estruturas observadas na base.

DEPÓSITOS DE ACRESCIMENTO LATERAL (LA) O elemento LA, aparece apenas no afloramento 6 sobrepondo ao elemento SB. A espessura máxima observada desse elemento é de $2,5 \mathrm{~m}$, o que indica acrescimento lateral de um pequeno canal. Esse elemento foi caracterizado principalmente pela diferença existente entre a direção de mergulho das superfícies limitantes nele contidas, e a direção das paleocorrentes indicada pelas estruturas sedimentares preservadas. Uma superfície de ordem 5 representa o limite inferior desse elemento, que possui ainda superfícies limitantes internas de ordem 3 , e uma superfície de ordem 4 que o limita superiormente. As superfícies de ordem 3 mergulham para leste $\left(\mathrm{N} 85^{\circ}\right)$ e estão separadas uma da outra por distâncias que variam de $40 \mathrm{~cm}$ a $1 \mathrm{~m}$. As litofácies que compõem o elemento LA são Ap e Aa com essas últimas mergulhando obliquamente às superfícies limitantes. Apenas nove medidas de paleocorrentes foram tomadas, devido a escassez de estruturas bem preservadas. $\mathrm{O}$ vetor médio possui azimute de $\mathrm{N} 141^{\circ}$, enquanto que $\mathrm{O}$ vetor magnitude obtido, foi de $83 \%$, mostrando boa orientação das estruturas sedimentares presentes no elemento. 
FINOS DE TRANSBORDAMENTO (FF) É composto quase que inteiramente pela litofácies $\mathrm{Fm}$, e secundariamente pela litofácies $\mathrm{Fl}$. Pode aparecer separado dos elementos arenosos por uma camada de conglomerado nas regiões proximais. Na parte norte da área estudada, aparece diretamente sobre os elementos arenosos e possui até três metros de espessura. A litofácies Fm, possui cor creme ou vermelha $\mathrm{e}$ é bastante físsil, quebrando-se em superfícies bastante irregulares.

DISCUSSÃo Os afloramentos da Formação Marizal na Bacia do Recôncavo evidenciam uma completa sequiência estratigráfica de depósitos proximais a distais, representados de sul para norte da área estudada, pelos elementos SG, GB, LS, SB, DA, CH, LA e FF. O elemento $S G$, é encontrado predominantemente na parte sul da área (afloramentos 2, 4 e 5) e representa a parte mais proximal de leques aluviais, onde fluxos de detritos foram os principais eventos deposicionais atuantes. Tanto a posição estratigráfica como espacial desse elemento, estão concordantes com as observações feitas nos vários afloramentos. Os fluxos de detritos verdadeiros estão representados pela litofácies $\mathrm{Cmf}$, que além de serem maciços, normalmente possuem concentração de clastos maiores na parte superior, o que representa provavelmente o êmbolo rígido (Lima \& Vilas Boas 1994). No afloramento 2 , há maior diversidade de litofácies, com uma variação significativa na quantidade de matriz. As três litofácies que o compõe (Cmc, Cma e Cmf), são depósitos típicos de regiões proximais de leques aluviais. As diferenças, em muitos casos, do arredondamento dos clastos, da quantidade de matriz e do tamanho dos cascalhos entre as camadas individuais, representam provavelmente fontes em diferentes locais, ou seja, o depósito é resultante do amalgamento de diferentes leques.

O elemento $G B$ representa a deposição em rios cascalhosos proximais de baixa sinuosidade, cujos processos deposicionais estão relacionados ao que Todd (1989), denominou de tapetes de tração (Lima \& Vilas Boas 1994). Desses processos, resultam as barras longitudinais e diagonais (terminologia de Hein \& Walker 1977), que geram uma estratificação horizontal com imbricação dos seixos. O não desenvolvimento de estratos cruzados, resulta da pouca profundidade do fluxo, não permitindo o desenvolvimento das camadas frontais (Church \& Gilbert 1975). A estrutura canalizada observada no afloramento 4 , é o produto da migração de um pequeno canal cortando as barras cascalhosas mais antigas. Isso confirma a observação de Miall (1985), de que bancos margeando canais de 1 a $2 \mathrm{~m}$ de altura imersos no elemento $\mathrm{GB}$, poderiam ser gerados dessa maneira.

Os elementos arenosos, marcam a transição das regiões proximal para distal do rio. Onde o elemento LS aparece, ele está disposto em lencol e representa um depósito de inundações rápidas (Miall 1977, 1985 e Rust 1978). Nestes locais, a profundidade do fluxo foi certamente tão rasa quanto aquela responsável pela deposição dos conglomerados estratificados. A velocidade do fluxo foi também alta, já que a litofácies predominante é $\mathrm{Ah}$, que representa regime de fluxo superior de leito plano. As litofácies Ab e Aa, representam possivelmente a deposição em partes ligeiramente mais profundas dos canais, em períodos em que a intensidade do fluxo foi menos intensa possibilitando para essa última o desenvolvimento de faces frontais. A litofácies $\mathrm{Ab}$ representa a deposição de dunas lavadas e provavelmente marca a transição entre as litofácies $\mathrm{Aa}$ e Ah, em fase final de inundação, já que, por vezes, essa litofácies aparece no topo da unidade depositada.

As macroformas de acrescimento a jusante (elemento DA) observadas em alguns locais, ocupavam certamente as partes mais rasas dos canais maiores, em períodos de menor velocidade da corrente. Essa afirmação é feita devido a ocorrência constante de lamitos sobre os estratos cruzados planares isolados, que eram depositados em períodos de aquiescência do fluxo, onde a água estagnava e depositava os finos sobre as barras transversais. Uma outra forte evidência para isso, é a presença da litofácies Ahi (arenito com laminação horizontal irregular) em nível estratigráfico semelhante aos dos estratos cruzados planares observados. Essa litofácies é interpretada como resultante do retrabalhamento das areias fluviais pelo vento, em períodos em que o nível da água esteve suficientemente baixo para que essas areias ficassem expostas subaereamente. Menos comumente, essas macroformas se desenvolveram em locais mais profundos. Isso é evidenciado quando há ausência de finos sobre as barras. Uma outra evidência para isso é o mergulho das camadas frontais, que é mais suave nas sequiências do afloramento 1 , por exemplo, (máximo de $22^{\circ}$ ) do que naquelas que ocorrem no afloramento 5 (máximo de $35^{\circ}$ ). No primeiro caso, a es- pessura das estruturas que compõem a macroforma, são bem maiores. A litofácies $A a$, que é representada por sequiências pouco espessas, e as seqüências menores da litofácies Ap, podem estar presentes e são resultantes de dunas 3D e 2D (Ashley 1990) respectivamente, migrando sobre as barras.

Seqüências solitárias de estratificação cruzada planar como a observada no afloramento 7, têm sido vastamente documentadas (Coleman 1969, Smith 1970, 1971,1972, Miall 1977, Cant \& Walker 1978, Crowley 1983 e Kirk 1983). Segundo Smith (1972), esta estrutura forma-se por migração para jusante nas faces de avalanche situadas nas margens das barras transversais. Cant \& Walker (1978), estudando o Rio "South Saskatchewan" no Canadá, deduziram que barras limitadas por faces de avalanche são feições geomorfológicas maiores, que predominam no leito do rio, e formam-se em áreas onde há expansão do fluxo, como na junção entre canais, ou em locais onde os canais se alargam. Essas barras servem de núcleo para a formação de feições ainda maiores denominadas de planícies de areia ("sand flats"). Essas planícies de areia, exibiriam tipicamente estratificação cruzada acanalada na base, sobreposta por uma seqüência de estratificação cruzada planar de grande porte. Esta última, seria capeada por uma complexa associação, de estratificação cruzada planar de menor porte do que as resultantes da migração das barras, estratificação cruzada acanalada e estratificação cruzada de pequeno porte, resultante da migração de marcas onduladas.

No caso observado da Formação Marizal, os arenitos que sobrepõem ao estrato cruzado planar de grande porte, podem apresentar-se maciços ou com estratificação cruzada acanalada em sequiências com até $15 \mathrm{~cm}$ de espessura e $1,5 \mathrm{~m}$ de largura. A presença dessas estruturas evidencia um estágio erosivo após a deposição da barra, que destruiu as estruturas menores que ocupavam o topo da planície de areia. Esse estágio se deu por uma elevação lenta do nível d'água, fazendo com que as dunas que migravam no fundo do canal, destruíssem as estruturas menores que ocupavam o topo de barras transversais (Jopling 1966, apud Smith 1970).

Crowley (1983), deduziu que as sequiências de estratificação cruzada planar de grande porte, representam também parte de um elemento maior, ao qual ele denominou de macroforma, que é composta por faces de deslizamentos maiores, faces de deslizamentos menores, lobos e aventais, e face dorsal. Esse elemento possui como estratificação interna uma seqüência com granocrescência ascendente, consistindo de três unidades: avental, camada frontal e camada de topo. Dessas unidades, apenas a camada frontal foi identificada no afloramento $7 \mathrm{da}$ Formação Marizal, não tendo sido observada nenhuma granocrescência ascendente.

Um consenso entre os diversos autores que estudaram depósitos atuais semelhantes ao observado no afloramento 7 da Formação Marizal, diz respeito a obliquiidade das faces de deslizamento das barras, com relação a direção principal dos rios nos quais elas migram. Smith (1972), em seus estudos no Rio Platte, revela dispersão relativamente ampla dos dados de paleocorrentes obtidos a partir dos estratos cruzados planares, embora o vetor médio corresponda a direção do complexo de canais principais. Cant \& Walker (1978), mostram desvio médio de $69^{\circ}$ para cinqüenta medidas feitas nas maiores barras encontradas no Rio South Saskatchewan no Canadá. Em contraste a isso, esses autores afirmam, que nas partes mais altas e centrais das planícies de areia, formadas em inundações maiores, as barras possuem camadas frontais mergulhando diretamente a jusante, fornecendo direção das correntes paralelas ao fluxo principal do rio. No afloramento 7, a direção das paleocorrentes fornecida pela estratificação cruzada planar, é de $\mathrm{N} 170^{\circ}$, enquanto que o vetor médio para a litofácies Aa é de $\mathrm{N} 132^{\circ}$, dando um desvio de $38^{\circ}$.

As ocorrências do elemento $\mathrm{SB}$, definem espessos campos de dunas migrando no fundo de canais de profundidade possivelmente superior a $3 \mathrm{~m}$, em período de fluxo alto, suficiente para transportar material grosso e formar estratos cruzados de grande porte. A espessura das seqüências (máximo de $60 \mathrm{~cm}$ ), representa a altura mínima das dunas, que migravam no fundo desses canais. As superfícies de $3^{\mathrm{a}}$ ordem observadas, são o registro dos estágios de mudança de fluxo. Elas sempre ocorrem acompanhadas de linhas de seixos, o que comprova o grande poder da corrente. Seqüências de estratos cruzados menos espessas (máximo de $30 \mathrm{~cm}$ ), representam a migração de dunas menores nas partes mais rasas dos canais, ou em canais menores. O tamanho dos estratos cruzados observados, sugere que a profundidade do fluxo foi maior do que aquela necessária para formar dunas no topo de uni- 

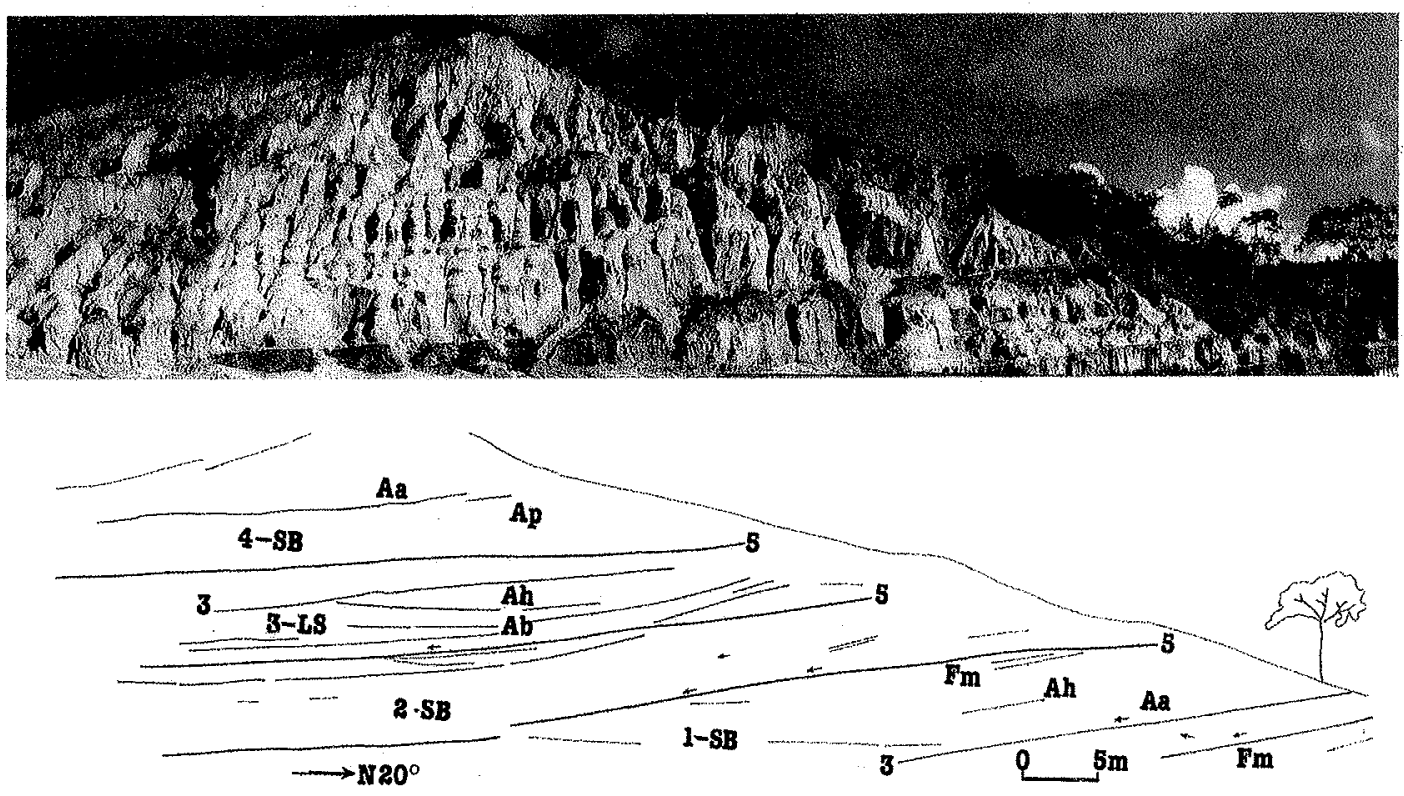

Figura 4 - Fotomosaico e perfil lateral do afloramento 08 , norte da área estudada. Nesta região, predominam os elementos arenosos. 5 : hierarquia das superfícies limitantes (ver Tabela l); $\rightarrow$ direçäo das paleocorrentes; Aa, Ah: código de litofácies (ver Tabela 2); 4-SB: código para elementos arquiteturais (ver Tabela $3) ; \rightarrow 20^{\circ}:$ Orientação do afloramento.

dades maiores, tais como barras transversais. Essa profundidade foi possivelmente maior que $3 \mathrm{~m}$, a julgar pelos estudos em rios recentes tais como o "South Saskatchewan" (Cant \& Walker 1978). Além disso, a feição canalizada (elemento $\mathrm{CH}$ ), observada no afloramento $1 \mathrm{da}$ Formação Marizal, mediu aproximadamente três metros de profundidade.

O elemento LA aparece no afloramento 6 migrando para leste, com as direções das paleocorrentes direcionadas para SE, o que indica que a essa feição arquitetural estava ligada ao banco direito do canal. Uma superfície erosiva corta a parte superior desse elemento e os blocos de argila encontrados ao longo dessa superfície são as evidências de que houve um elemento FF, que é comumente encontrado no topo do elemento LA (Miall 1985). Baseado na espessura do elemento, a profundidade do canal em que ele foi formado, foi de no mínimo $3 \mathrm{~m}$. Segundo Allen (1965), que diz que a largura do depósito de acrescimento lateral é de aproximadamente dois terços da largura do canal, este deveria ter pelo menos $40 \mathrm{~m}$ de largura. O mergulho de cerca de $5^{\circ}$ para as superfícies limitantes revelam no entanto, razão largura profundidade bem maior que 13 (Leeder 1973), que é o valor aproximado ao se dividir 40 por 3 que são respectivamente a largura e profundidade estimada para o canal. Essas diferenças devem refletir a quantidade de erosão ao qual o elemento foi submetido. O elemento LA observado no afloramento 6 , é semelhante ao descrito por Allen (1983), com granulometria variando de fina a seixosa, e com depósitos residuais compostos por calhaus e matacões, definindo um rio de sinuosidade intermediária a alta. No caso da Formação Marizal, esses canais devem ter sido poucos comuns.

Com relação ao elemento $\mathrm{CH}$, seguindo a terminologia de Friend (1983) e de Blakey \& Gubitosa (1984), a estrutura observada no afloramento 1 pode ser classificada como um "canal móvel", onde a razão largura/profundidade é maior que 15. Canais móveis são assim chamados, porque eles são preenchidos por um processo de migração do canal, ou mudança da posição dentro de um canal principal único (Miall 1985). A diminuição para cima das estruturas bem como da granulometria, é típica de preenchimento de canais, onde a intensidade do fluxo decresce continuamente, a medida em que o canal vai sendo preenchido. $O$ fato das estruturas menores do topo, migrarem em direção diferente com as estruturas da base, representam o menor poder da corrente nos estágios finais do preenchimento do canal (Miall 1985). Essas estruturas (principalmente marcas onduladas), têm valor muito reduzido como indicadoras de paleocorrentes em ambientes fluviais (Miall 1980 e 1985).

O elemento FF representa os depósitos de transbordamento de canais, que foram possivelmente acrescidos por eventos sucessivos de inundação. Esse elemento em conjunto com os elementos arenosos, exibe no afloramento 4, um ciclo típico de preenchimento de canal por agradação vertical (LS-SB-OF), mostrando uma sucessão com granodecrescência ascendente (Miall 1985), que nesse caso é interpretado como resultante da deposição durante eventos dinâmicos, tais como, inundações rápidas e de grande magnitude. Este elemento aparece representado basicamente pela litofácies Fm que pode ser observada sobrepondo a conglomerados maciços, ou associada com camadas arenosas. Onde associada com os corpos conglomeráticos, os finos maciços formam camadas de até $1 \mathrm{~m}$ de espessura, e podem conter lentes de arenito no seu interior. Em associação com os arenitos que ocorrem mais comumente na faixa norte da área estudada, as camadas mais espessas da litofácies Fm (mais que três metros de espessura), ocorrem sobrepondo a corpos arenosos também espessos. As superfícies que separam os arenitos dos lamitos, nesse último caso, podem ser marcadas por uma fina camada de conglomerado.

A presença de camadas mais espessas da litofácies Fm, e conseqüentemente do elemento $\mathrm{FF}$, são melhor documentadas em rios meandrantes (Ghosh 1987, Kraus \& Middleton 1987, e outros), e poucas são as referências sobre a ocorrência dessa litofácies em rios entrelaçados. Williams \& Rust (1969) observaram camadas relativamente espessas da litofácies $\mathrm{Fm} \mathrm{em}$ rios entrelaçados, no noroeste do Canadá, onde os finos maciços foram depositados e preservados em canais abandonados, com o aporte de sedimentos ocorrendo por inundações ocasionais. Billi et al. (1987), estudaram depósitos resultantes de rios cascalhosos de baixa sinuosidade, na Itália, onde pacotes espessos da litofácies Fm, foram depositados e os interpretaram, como depósitos de transbordamento. Na Formação Marizal, as camadas mais espessas da litofácies Fm, são semelhantes as descritas por Billi et al. (1987), com algumas delas possuindo na base, finas camadas de conglomeriklon. que são consistentes com os processos de escavação c prechlihmentu ("scour and fill") durante processos de inundações cxtremas (Limil de Vilas Boas 1996).

CONCLUSÕES As partes proximais da Formação Marizal, repre sentadas pelos conglomerados que compõem os elemenlos S S $i \mathrm{C} G \mathrm{~GB}$, revelam que várias são as fontes desses sedimentos, onde clastos de rochas metamórficas bandadas (alto grau de metamorfismo), quartzitos, rochas ígneas básicas, além de cascalhos intrabasinais foram observados. As direções das paleocorrentes medidas no elemento $\mathrm{SG}$, mostram que vários foram os leques atuantes, e que esses se dispunham em diferentes direções de propagação do fluxo. No afloramento 3 por exemplo, as direções das paleocorrentes para a litofácies Cma dão um vetor médio para noroeste $\left(\mathrm{N} 339^{\circ}\right)$, enquanto que no afloramento 2 , as paleocorrentes no elemento $S G$ seguiam para sudeste $\left(\mathrm{N} 105^{\circ}\right)$. 
O elemento GB representa a deposição em riós cascalhosos largos, rasos e de baixa sinuosidade, nas regiões proximais dos leques aluviais. A magnitude dos eventos sísmicos na região de deposição desse elemento, não foi suficientemente forte para gerar pacotes espessos de fluxos gravitacionais de sedimentos, como observado nos afloramentos 1,6, e 7, e na base do afloramento 2. Apesar de menos intensos dos que os aqueles que geraram os elementos SG, a freqüência dos eventos foi alta, já que uma quantidade muito grande de falhamentos penecontemporâneos é observada por todo o elemento GB.

Os elementos arquiteturais arenosos e lamosos, fornecem dados que definem a sinuosidade, o regime de fluxo predominante, a profundidade e a largura dos canais, além de fornecer evidências dos vários subambientes que compõem os rios, tais como planícies de inundação, canais, macroformas e depósitos de transbordamento. As diversas estruturas sedimentares presentes nos elementos arenosos, revelam uma mudança na direção das paleocorrentes, entre as regiões proximais dos leques (direção para ENE) e a planície de entrelaçamento (direção para SSE).

Os perfis laterais elaborados a partir dos fotomosaicos, mostram a variação entre dois domínios de estilo fluvial das regiões proximais para as regiões distais (Figura 5). O primeiro domínio representa rios cascalhosos rasos, largos e de baixa sinuosidade, resultando no elemento GB. O segundo, é o resultado de rios rasos e largos, com carga de leito arenosa e com sinuosidade baixa a intermediária. A profundidade dos canais mais profundos devem ter atingido um máximo de $3 \mathrm{~m}$, onde campos de dunas de até $1 \mathrm{~m}$ de altura, migraram no leito desses canais. No entanto, a presença de lençóis arenosos compostos por estratos cruzados menores e pelas litofácies $\mathrm{Ah} \mathrm{e} \mathrm{Ab}$ que formam o elemento LS, mostram que a profundidade da maioria dos canais, foi muito pequena. Isso faz com que seja difícil definir no campo, os ban-

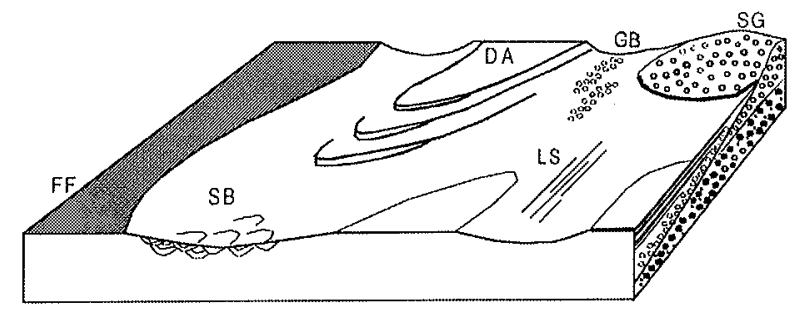

Figura 5 - Bloco diagrama idealizado para a paleogeografia da Formação Marizal na Bacia do Recôncavo. Nos ambientes proximais, tem-se o dominio dos elementos cascalhosos ( $S G$ e GB), enquanto que nas partes mais distais, predominam os elementos arenosos (DA,SB,LS) e lamosos $(F F)$.

cos que margeiam a maioria dos canais, já que esses foram interpretados como depósitos em lençol, na terminologia de Friend (1983). Outra razão para a ausência desses bancos, é a falta de coesividade em aluviões dominados por areia (Miall \& Turner-Peterson 1989).

Acumulações locais espessas das litofácies $\mathrm{Ah}$ e Ab, sugerem fluxo de alta energia que caracterizam condições de regime de fluxo superior de leito plano, ou um regime de fluxo de transição entre o estágio inferior e o superior. Essas acumulações, evidenciam um estilo deposicional típico de rios efêmeros com descarga errática, semelhantes ao sistema fluvial proterozóico do norte da Noruega (Hjellbakk 1997), ou daqueles que sofrem inundações periódicas, sugerindo um clima árido a semi-árido durante a deposição da Formação Marizal. Ocorrências de ciclos evaporíticos que sobrepõem a Formação Marizal na região de Camamu no sul do Estado da Bahia e de sedimentos evaporíticos que a sobrepõe na Bacia de Tucano são evidências adicionais do clima árido que predominou durante a deposição da Formação Marizal.

\section{Referências}

Allen J.R.L. 1965. The sedimentation palaegeography of Old Red Sandstone of Anglesey, North Wales Yorks, Geol Soc. Proc/, 35:139-185.

Allen J.R.L. 1983. Studies in fluviatile sedimentation: bars, bar complexes and sandstone sheets (low-sinuosity braided streams) in the Brownstones (L. Devonian), Welsh

Almeida A \& Ghignone JI 1962 Geologia do Centro Oeste da Bacia de Tucano, área de Euclides da Cunha PETROBRÁS (Rel. Int. 688).

Ashley G.M. 1990. Classification of large-scale subaqueous bedforms: a new look at na old problem. Jounn. Sediment. Petrol. 60:160-162

Billi, P. Magi M Sagri M 1987 Coarse-grained low sinuosity rivers deposits: examples from Plio-Pleistocene, Valdarno Basin. In; F.G. Ethridge, R.M. Flores, M.D. Harvey (eds) Recent Developments in Fluvial Sedimentology. Soc. Econ. Paleontol. Mineral., Spec. Publ., 39:197-204.

Blakey R.C. \& Gubitosa R. 1984. Controls of sandstone body geometry and architecture in the Chinle Formation (Upper Triassic), Colordo Plateau. Sediment. Geol.., 38:51-86.

Brazil J.J. 1947. Resume of geologic reconnaissance of the north half of the Bahia sedimentary embayment northeast Bahia and west edge of Sergipe. S.1, PETROBRÁS (Rel. Int. 20)

Cant D.J. \& Walker R.G. 1978. Fluvial processes and facies sequences in the sandy braided South Saskatchewan River, Canada. Sedimentology, 25:625-648.

Church $M$ \& Gilbert $R$. 1975. Proglacial fluvial and lacustrine environments. In:JOPLING,A.V. \& Mc DONALD,B.C. eds. Glaciofluvial and glaciolacrustine sedimentation Soc. Econ. Paleont. Min., Spec. Public. 23:22-100.

Coleman J.M. 1969. Brahmaputra River; channel and sedimentation. Sediment. Geol. 3:129-239.

Cowan E.J. 1991. The large-scale architecture of fluvial Westwater Canyon Member Morrinson Formation (Jurassic), San Juan Basin, New Mexico. In: A.D. Miall \& N Tyler (eds.) The three dimensional facies architecture of terrigenous clastic sediments and its implications for hydrocarbon discovery and recovery. SEPM Concepts in Sedimentology and Palcontology, 3:80-93.

Crowley K.D. 1983. Large Scale bed configurations (macroforms), Platte River Basin Colorado and Nebraska: Primary structures and formative processes. Geol. Soc. Am. Bull. 94:117-133.

Curray J.R. 1956. The analisys of two dimensional orientation data. J. Geol., 64:117-131.

Fonseca J.I. 1961. Geologia da área centro norte do Recôncavo, PETROBRAS(Rel. Int. 481)

Friend P.F. 1983. Toward the field classification of alluvial architecture or sequence. In: J.D Collinson \& J. Lewin (eds.) Modern and Ancient Fluvial Systems. Int. Assoc. Sediment Publ 6.345-354.

Ghignone J I. 1963. Geologia do flanco oriental da Bacia de Tucano Norte do Vaza dos Barris ao São Francisco, PETROBRÁS (Rel.Int. 688)

Ghosh S.K. 1987. Ciclicity and facies characteristics of alluvial sediments in the Monongahela Dunkard Groups, Central West Virginia. In: F.G. Ethridge, R.M. Flores, M.D. Harvey (eds.). Recent Developments in Fluvial Sedimentology. Soc. Econ. res, M.D. Harvey (eds.). Recent Developments
Paleontol. Mineral.,Spe. Publ., 39:229-242.

Hein FJ. \& Waiker R.G. 1977. Bar evolutuon and development of stratification in the gravelly, braided, Kicking Horse River, British Columbia. Can. J. Earth Sci, 14:562grave.

Hjellbakk A. 1997. Facies and tluvial arcitecture of a high-energy braided river: the Upper Proterozoic Seglodden Member, Varanger Peninsula, northern Norway. Sediment. Proterozoic Seglodden

Kitk M. 1983. Bar developments in a fluvial sandstone (Westphalian"A"), Scotland. Sedimentology, 30:727-742

Kraus M.J. \& Middleton L.T. 1987. Contrasting architecture of two alluvial suites in different structural settings. In: F.G. Ethridge, R.M. Flores, M.D. Harvey (eds.) Recent Developments in Fluvial Sedimentology'. Soc. Econ. Paleontol. Mineral., Spe
Publ., 39:243-252

M.R. 1973. Fluviatile fining upward-cycles and the magnitude of paleochannels. Geol. Mag., 110:265-276.

Lima C.C.U 1991. Reconstrução Arquitenural da Formacão Marizal na Bacia do Recôncavo, Bahia Brasil. Dissertação de Mestrado, UFBA. 115p (inédito)

Lima C CU. \& Vilas Boas G.S. 1990. Elementos arquiteturais da Formação Marizal nas proximidades de Camaçari, Ba. SBG. In: Congr. Bras. Geol., 36 Natal, 1990. Bole im de Resumos. Natal, P.21.

Lima C.C.U. \& Vilas Boas G.S. 1994. Mecanismos de transporte e deposição dos conglomerados da Formação Marizal (Cretáceo Inferior), na Bacia do Recôncavo, Bahia Brasil. Rev. Bras. Geoc. 24:240-246.

Lima C.C.U. \& Vilas Boas G.S. 1996. Caracterização da faciologia areno-lamosa da Formação Marizal na Bacia do Recôncavo-BA. SBG. In: Congr. Bras. De Geol., 39 Malvador Ancis 01:154-156.

Miall A. 1977 A review of the braided river depositional environment. Earth-Sci.Rev. 13:1-62.

Miall A.D 1978. Lithofacies types and vertical profile models in braided river deposits: summary. In. Miall, A.D. (ed.) Fluvial Sedimentology. Can.Soc. Petrol. Geol. Mem. $5: 597-604$.

Miall A.D. 1980. Ciclicity and the facies models concept in fluvial deposits. Bull. Can Petrol. Geol., 28:59-60.

Miall A.D 1985 Architectural-element analysis: a new method of facies applied to fluvial deposits. Earth-Sci. Rev. 22:261-308.

Miall A. 1988 . Architectural element and bounding surfaces in fluvial deposits: Anatomy of the Kayenta Formation (Lower Jurassic), Southwest Colorado. Sediment. Geol 55:233-262

Miall A.D 1996. The Geology of Fluvial Deposits:Sedimentary Facies, Basin Analysis and Petroleum Geology. Springer-Verlag Berlin, Heiderberg, New York 582pp.

Metroleum Geology'. Springer-Verlag Berlin, Heiderberg, New York Member; Morrinson Formation (Jurassic), San Juan Basin, Colorado Plateau Sediment. Geol., 63:21-60.

Rust B R 1978. Depositional models for braided alluvium In Miall,A D. (Editor). Fluvia Sedimentology. Can. Soc. Petrol. Geol. Memoir 5:605-625.

Santos E.R. 1962. Geologia da área Poco Verde-Adustina, Leste Da Bacia de Tucano PETROBRÁS ( Rel. Int. 527)

Smith N.D. 1970. The braided stream depositional environment; comparison of the Platte River with some Silurian clastic rocks, north central Appalachians. Geol. Soc. Am. Bull., 81:2993-3014.

Smith N.D. 1971. Transverse bars and braiding in the lower Platte River, Nebraska. Geol. Soc. Am. Bull., 81:3407-3420.

Smith N.D. 1972. Some sedimentological aspects of planar cross-stratification in a sandy braided river. J. Sediment. Petrol., 42: 624-634.

Todd S.P. 1989. Stream-driven, high-density gravelly traction carpets: possible deposits in the Trabeg Conglomerate Formation, SW lreland and some theoretical consideration of their origin. Sedimentology, 36:513-530.

Viana C.F. Gama Júnior E.G., Simōes I.A., Moura J.A., Fonseca J.R., Alves R.J. 1971 Revisão estratigráfica da Bacia Recôncavo/Tucano. Bol. Tec. Petrobrás, 3/4:157 192.

Williams P.F. \& Rust B.R. 1969. The sedimentology of a braided river. J. Sediment. Petrol. 39:649-679.

Manuscrito A-1131

Recebido em 30 de outubro de 1999

Revisão dos autores em 15 de junho de 2000 Revisão aceita em 25 de junho de 2000 